\title{
Panel Board From Coconut Fibre And Pet Bottle
}

\author{
Norhayati Ngadiman ${ }^{1,}$, Masiri Kaamin ${ }^{1}$, Aslila Abd. Kadir ${ }^{1}$, Suhaila Sahat ${ }^{1}$, Aziza Zaini ${ }^{1}$, \\ Siti Raihana Nor Zentan ${ }^{1}$, Nur Ain Ahmad ${ }^{1}$, and Wan Haizatul Aisyhah Wan Amran ${ }^{1}$ \\ ${ }^{1}$ Center for Diploma Studies, Universiti Tun Hussein Onn Malaysia (UTHM), Malaysia
}

\begin{abstract}
The rate of global deforestation and its impact on the environment has led particle board manufacture to search for alternative feedstock, especially in countries where wood is less available compared to other cellulosic natural product. Based on the properties of coconut fibre and PET bottle, these two materials can be recycle as raw material for manufacture of panel board. As for this study, the coconut fibre were used as the filler and PET bottle as outer lining of the panel board. Two types of coconut fibre were used which are grinding and un-grinding coconut fibre. At first, the coconut fibre are undergoes softening, grinding, drying and sieving process, while PET bottle was cleaning, shredding, sieving before compacted using hydraulic hot press machine. There are four types of testing that been carried out which are swelling, water absorption, Modulus of Elasticity (MOE) and Modulus of Rupture (MOR). The result show the conventional board has the highest value for MOE test, so it's indicate that the conventional board is less strength from the coconut fibre board. As for water absorption test, the average water absorption of coconut fibre based panel board is less than conventional board. Overall, the coconut fibre board is better than conventional panel board because coconut fibre board are less swelling, has low water absorption, high modulus of rupture and low modulus of elasticity. Based on the finding, this coconut fibre panel board has potential as a stronger and long-lasting panel board than the conventional board in the market. Other than that, the panel also have their own aesthetic value since the recycled plastic bottle used as outer lining is colourful and giving aesthetic value.
\end{abstract}

\section{Introduction}

The use of renewable resources such as agriculture residues is gaining increase interest in production of particle board. Coconut is a renewable resource and a natural fibre extracted from the husk of coconut and used in product such as floor. Coconut fibre, also known as coir, comes from the inner husk of coconuts and it most widely grown nut in the world and contribute significantly to the economy of many tropical areas. It's used in manufacturing map, rope and landscaping. However, most of coconut fibre waste are not be utilize and it end up as waste that can effect on the water surface, groundwater and soils because it contain salts and others chemical.

\footnotetext{
* Corresponding author: nryati@uthm.edu.my
} 


\subsection{Coconut Fibre}

Coconut fibre also known as coconut coir is a fibrous material extracted from the husk of coconut. Commonly the coconut fibre is separated from the husk by mechanical method even though it's also can be separated using chemical and biological method [1]. Brown fibres fibre extracted from matured coconuts are thick, strong and have high abrasion resistance, while white fibres are smoother, finer and weaker [2]. Table 1 is showing the chemical composition of coconut fibre. Coconut fibre is the hardest natural fibre because high content lignin in coconut fibre up to more than $30 \%$ that make the fibre tougher and stiffer by providing plant tissue and individual fibre with compressive strength and stiffen the cell wall of the fibre in order to protect the carbohydrates from chemical and physical damage [3]. According to Ali (2010), coconut fibres are capable of taking strain 46 times more than that of other fibres. Moreover, coconut fibre does not loose strength on storage and expose to sunlight [1]. Table 2 shows the physical properties of coconut fibre. The value density of coconut fibre is important to determine the total mass needed to produce the coconut fibre panel board.

Table 1. Chemical composition coconut fibre [3].

\begin{tabular}{|c|c|}
\hline Chemical Composition & Percentage (\%) \\
\hline Halocellulose & 56.3 \\
\hline$\alpha$-cellulose & 44.2 \\
\hline Lignin & 32.8 \\
\hline Ash & 2.2 \\
\hline
\end{tabular}

Table 2. Physical properties of coconut fibre [4].

\begin{tabular}{|l|c|}
\hline \multicolumn{1}{|c|}{ Physical Properties } & Coconut Fibre \\
\hline Density $\left(\mathrm{g} / \mathrm{cm}^{3}\right)$ & 1.2 \\
\hline Elongation at break (\%) & 30 \\
\hline Tensile strength (Mpa) & 175 \\
\hline Young Modulus (Gpa) & $4-6$ \\
\hline Water Absorption (\%) & $130-180$ \\
\hline
\end{tabular}

\subsection{Polyethylene terephthalate (PET)}

PET bottle widely used drink bottle and the PET bottle waste took long times to decay. Polyethylene terephthalate or also known as polyethylene terephthalate, commonly abbreviated PET, PETE, or the obsolete PETP or PET-P, is the most common thermoplastic polymer resin of the polyester family and consists of polymerized units of the monomer ethylene terephthalate, with repeating $\left(\mathrm{C}_{10} \mathrm{H}_{8} \mathrm{O}_{4}\right)$ units [5]. Recycle PET is has the number "1" as and recycling symbol. PET is colourless in its natural state. Based on how it is processed, PET can be semi-rigid to rigid, and it is very lightweight. PET becomes white when exposed to chloroform and also certain other chemicals such as toluene [6]. About $60 \%$ crystallization is the upper limit for commercial products, with the exception of polyester fibres [7]. Due to its significant water and moisture resistance, it is widely used in making plastic bottles for soft drinks as shown in Fig. 1 [8]. One of the most important characteristics of PET is referred to as intrinsic viscosity (IV) [9] that, shows the thickness of the carbonated soft drink is bigger than plastic bottle. As the cover of the panel board, the PET plastic must be rough to prevent the filler from the termite while the carbonated soft drink also can protect the filler from the water because the PET plastic has lower water absorption. 
The use of coconut fibre in the manufacture of furniture is increasingly widespread due to its properties. Previous research shows coconut fibre is stronger than wood fibre. Meanwhile, PET bottles are excellent barrier materials and are widely used for soft drinks. Therefore, properties coconut fibre of and PET bottle have been study carefully in order for the researcher to make sure these material as panel board main raw material. Thus, this project used coconut fibre to replace the wooden fibre as the filler of the panel and recycled PET bottle as a cover for the panel. The purpose of this panel board is to reduce waste of coconut fibre and plastic bottle (PET) and transform into useful product. In the other side, one of the problems for existing board now is easily expand and cannot withstand to water. This project is assign to; (1) design and produce a panel board using coconut fibre as filler and plastic as the outer lining and (2) test the Modulus of Elasticity, Modulus of Rupture, swelling and water absorption of the coconut fibre panel board.

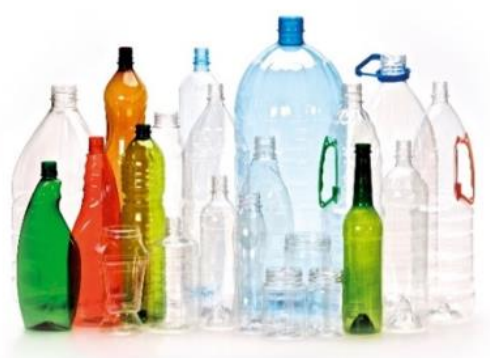

Fig. 1. Recycled plastic Bottle (PET).

\section{Methodology}

\subsection{Flowchart Process}

According to the flowchart in Fig. 2, the first phase is to produce the panel board is preparing raw materials before undergoes the softening process. Then, the softening process took 24 hours and after that, it undergoes the cleaning process. Next, crushing and grinding the coconut fibre. Lastly, sieve the grinding coconut fibre to remove the dusk. While the PET plastic bottle need to be cleaned before shredding used the plastic granulator machine. The second phase is making the panel board. There is only one process which is compact the grinded coconut fibre and un-grinded coconut fibre. Then, the PET plastic will be compact as the outer layer of the panel board. In the third phase the project, the panel board sample are cut in smaller size sample before testing were carried out. After that, undergoes the finishing process the sample were tested according to the standard test applied on the panel which are modulus of elasticity, modulus of rupture, swelling and water absorption. The result will be compare to the conventional panel. 


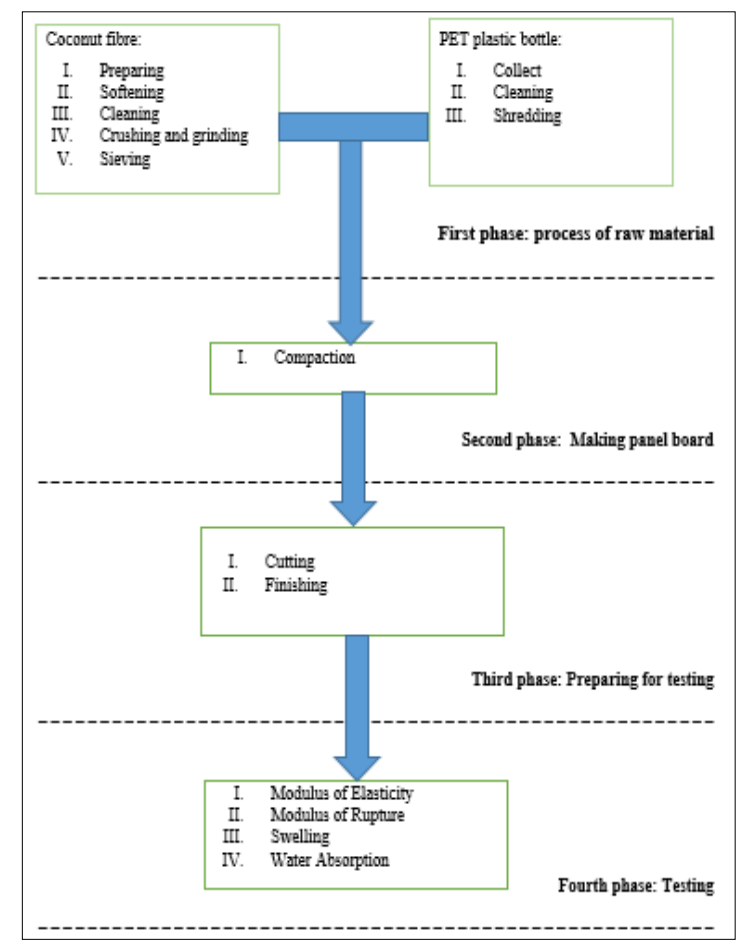

Fig. 2. Flowchart of panel board process.

\subsection{Coconut fibre process}

First step to produce the coconut fibre as the raw material is prepare the $5 \mathrm{~kg}$ of coconut fibre. Then, the coconut fibre need to be softening so it will be easier to use. The softening process will take 24 hours to be soak into the water and then remove the outer layer and cut the coconut husk into a small size. The coconut husk will be dried into the oven with $80^{\circ} \mathrm{C}$ for 20 minutes to ensure that all the water content is fully condense and dried coconut husk before put into the fibre process machine to separate the coconut peat and the coconut fibre. Coconut fibres are commercial available in three forms, namely bristle (long fibres), mattress (relatively short) and decorticated (mixed fibres) [2]. Therefore, the coconut fibre was divide into two equal weight because half of coconut fibre will undergo the grinding process while the other half will remain the original size as shown in Fig. 3 and Fig. 4. The physical appearance to make two different sample according to the physical appearance of coconut fibre. Then, sieve the grinding coconut fibre used $300 \mathrm{~mm}$ and $63 \mathrm{~mm}$ sieve size to remove the dusk. After that, the coconut fibre and glue is mixing each other using the ratio $70 \%$ of the coconut fibre while $30 \%$ of the glue from the mass of the panel board and need to be compact to get a thin layer of coconut fibre. Lastly, cut the layer into $50 \mathrm{~mm}$ x $50 \mathrm{~mm}$ measurement and $12 \mathrm{~mm}$ thickness. 


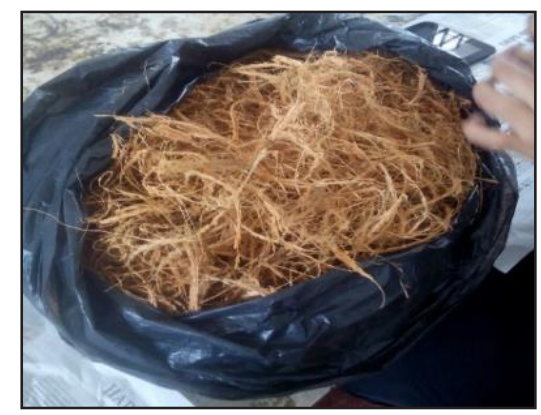

Fig. 3. Coconut fibre before grinding.

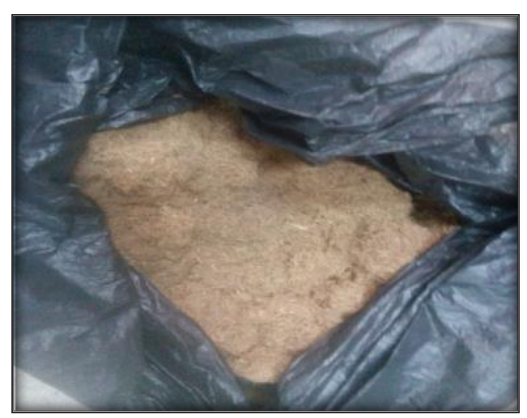

Fig. 4. Coconut fibre after grinding.

\subsection{Polyethylene Terephthalate (PET) Bottle Process}

For the first process of PET plastic bottle is collecting the bottle until it weight $1 \mathrm{~kg}$ and then, cleaning the bottle with wash used water and dried it naturally, it will then cut into smaller pieces. This is because the Plastic Granulator Machine cannot be operated with large chunk of plastic. As for the precaution the plastic is need to be clean and dry to prevent the damage to the machine. Fig. 5 shows the shredded the recycle PET bottle.

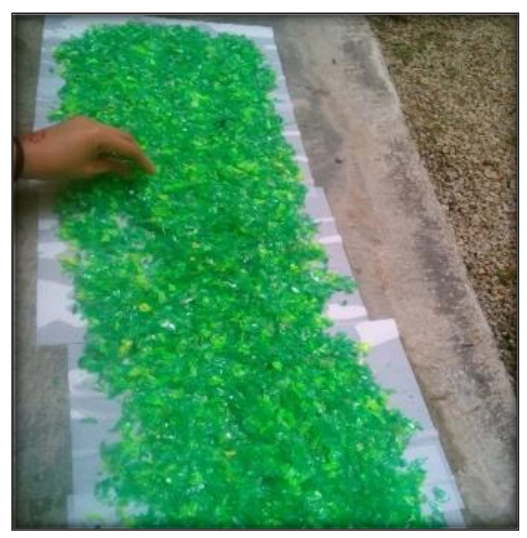

Fig. 5. Shredded recycle PET. 


\subsection{Panel board process}

Process of making of panel board are including compaction, cutting into standard size and finishing process. Firstly, the compaction process will compact the grinded coconut fibre used hydraulic type hot or cold machine and set the machine with $170{ }^{\circ} \mathrm{C}$. For one panel, the mass of coconut fibre is 521.58 grams and mass of urea gam is 223.53 grams with 308 $\mathrm{mm} \times 288 \mathrm{~mm} \times 12 \mathrm{~mm}$ size of the mould. The same process same goes to the un-grinding coconut fibre. There are two panel for each sample which are one will covered with PET plastic while another one will not covered with PET plastic. Then, for the sample that covered with PET plastic, the PET plastic will be compact as the outer layer of the panel board with the same machine and same temperature to produce the aesthetic value. For the preparing panel for testing, the sample will be cut into area of $50 \mathrm{~mm}$ x $50 \mathrm{~mm}$ for water absorption and swelling test while cutting the sample into area of $240 \mathrm{~mm}$ x $50 \mathrm{~mm}$ for modulus of rupture and modulus of elasticity test. Then, the finishing process for the sample is shellac the outer layer for the $50 \mathrm{~mm}$ x $50 \mathrm{~mm}$ sample to undergo the water absorption and swelling test and want to compare with the conventional panel with the same condition.

\section{Results and Discussions}

\subsection{Modulus of Elasticity (MOE)}

This method of testing is used to determine the coconut fibre with grinding process, the coconut fibre with un-grinding process and standard panel board behaviour under an axial stretching load. The maximum load of this three sample being compared. The area of the panel board sample is $50 \mathrm{~mm} \times 240$ while the volume is $50 \mathrm{~mm}$ x $240 \mathrm{~mm} \times 12 \mathrm{~mm}$. The Fig. 6 show the graph of the average of the modulus of elasticity of grinding sample is 1721.33 MPa, un-grinding sample is $1163.90 \mathrm{MPa}$ and conventional sample is 2720.33 $\mathrm{MPa}$. The un-grinding sample has the lowest modulus of elasticity followed by the grinding sample and conventional sample. The lower the modulus of elasticity, the higher the stiffness of the sample. The stiffness of un-grinding sample is the highest because it has long physical appearances that bond together to improve the strength of the panel board.

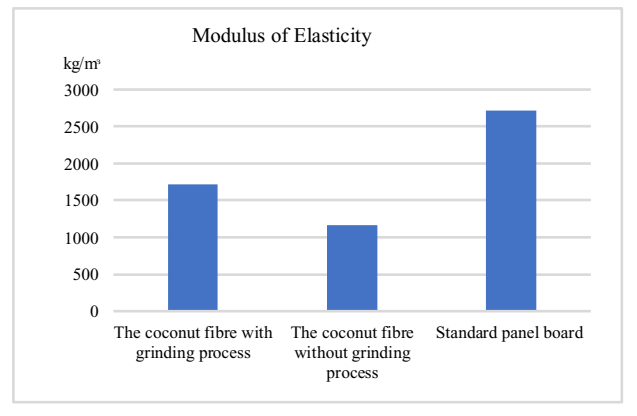

Fig. 6. Graph modulus of elasticity.

\subsection{Modulus of Rupture (MOR)}

The Fig. 7 shows the graph of average of the modulus of rupture of grinding sample is $1.914 \times 10^{-5} \mathrm{kN}$, un-grinding sample is $2.205 \times 10^{-5} \mathrm{kN}$ and conventional sample is $1.881 \mathrm{x}$ $10^{-5} \mathrm{kN}$. The un-grinding sample has the highest modulus of rupture followed by the 
grinding sample and conventional sample. The un-grinding sample has the long physical appearance which will bond to each other and cause the higher strength compared to the other sample. The highest the modulus of rupture, the highest the strength of the sample. The un-grinding coconut fibre is stronger to load bearing capacity than the conventional board and grinding coconut fibre.

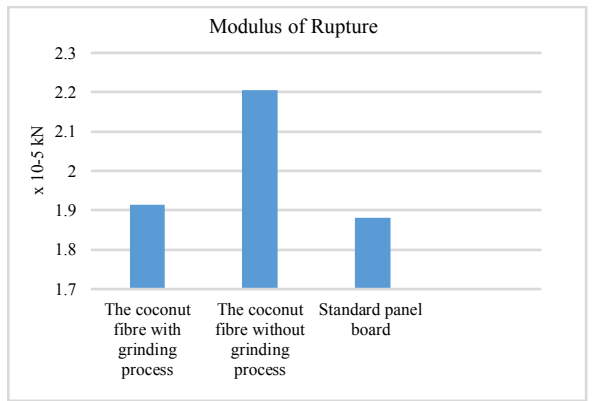

Fig. 7. Graph modulus of rupture.

\subsection{Water Absorption Test}

The Fig. 8 show the graph that the highest water absorption is conversional panel board with the average percentage of water is $67.08 \%$. The second highest is un- grinding sample of panel board is $59.84 \%$ while the lower average water absorption is grinding sample of panel board is $56.21 \%$. The grinding sample less absorption of water followed by the ungrinding sample panel board and the conventional panel board. In the other shell, grinding sample is the lower water absorption because the physical appearances of the fibre was grinding into the small size and the bond between coconut fibre bindings more strong to reduce the water absorb and fill in the pores. The grinding coconut fibre does not absorb more water because this panel is more compact.

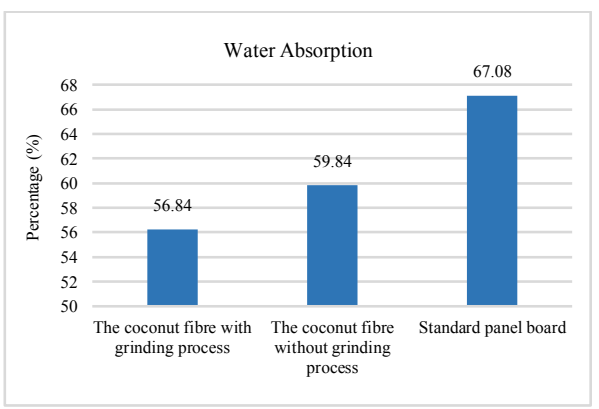

Fig. 8. Graph of water absorption.

\subsection{Swelling Test}

The Fig. 9 show the graph of the depth of the conventional panel board swelled is $1 \mathrm{~mm}$ compared to the grinding sample and un-grinding sample. The size of the grinding sample and un-grinding sample after immersed remain same as before immersed because lignin of the coconut fibre reduce the thickness swelling of the sample. 


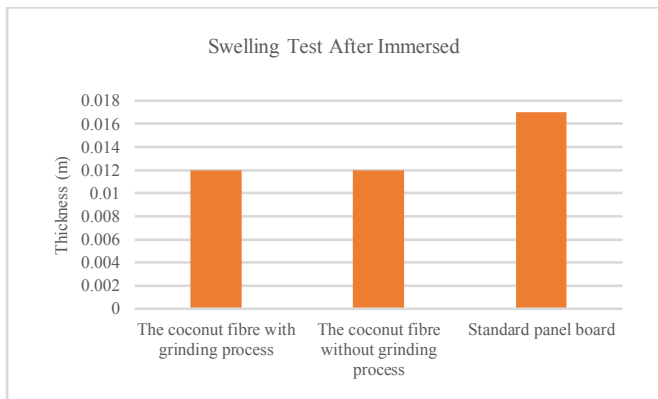

Fig. 9. Graph swelling test after immersed.

\subsection{Discussions}

For overall, according to the result from the four standard test that have been done, the ungrinding panel board is the stronger followed by the grinding coconut fibre and conventional panel board. The un-grinding panel board is the best because it have no swelling, less water absorption, high modulus of rupture and low modulus of elasticity. All of this test are used few constant condition such as, the size of the panel board, time taken to immersed the panel board and the room temperature of the place experiment. This project was achieved the expected outcome to become stronger than the normal panel in market. Table 3 show the advantage of panel board using coconut fibre and recycled plastic compared to wooden panel board. The coconut fibre panel board able to bear huge load in certain range which is larger than the conventional panel could do because high content of lignin in coconut fibre. Moreover, it is also long-lasting and has low absorption of water since plastic are not permeable to water. Lastly, this panel board has its own aesthetic value.

Since, the PET plastic were used as the outer lining so it has colourful design and give the aesthetic value as the cover most similar to mosaic. Other than that, this panel is also slightly rough but not harmful to the user. The temperature of the hydraulic type hot or cold machine should be set up to be higher than $170{ }^{\circ} \mathrm{C}$ to make sure the PET plastic will bonding together with the panel board as the cover layer. Other than that, the plastic also should be undergoes the layering process to produce the smooth of the outer layer and fully melt to gain more aesthetic value. To overcome the glue to be spot at one point on the panel board in the mixing process, spray the urea glue used the air compressor on the coconut fibre to make sure the urea glue spread evenly to all part of coconut fibre.

Table 3. Advantage of panel board using coconut fibre and recycled plastic compared to wooden panel board.

\begin{tabular}{|l|l|}
\hline \multicolumn{1}{|c|}{ Wooden panel board } & Panel board using coconut fibre and recycled plastic \\
\hline Bear a huge load in certain range is small & Bear a huge load in certain range is large \\
\hline Not long-lasting & Long-lasting \\
\hline High absorption of water & Low absorption of water \\
\hline No aesthetic value & Has aesthetic value \\
\hline Smooth surface & Slightly rough surface \\
\hline
\end{tabular}




\section{Conclusions}

The objective of the study was achieved which is the reason for the coconut fibre as the filler for the panel board and PET plastic as the cover is because its own strength and weakness which can be improvised. Based on the criteria to get a good panel board, test on the strength and durability of the panel can be derived. Thus, the panel board which has an aesthetic value can replace the market of wooden panel board and solve the issue about water pollution in the country. The application of the project is can be replace the medium fibre board in the market according to the size and finding such as closet, cabinet, table and the relevant product to the medium board. The product of the study also can be commercial with the low cost and more advantages than the conventional panel board. There are possibility of this coconut fibre panel board has lower cost than the normal panel board since it is using the recycled waste product and do not need any chemical treatment for processing raw materials.

The authors would like to express our deepest gratitude to all parties who have contributed to this research, especially to Short Term Grant (STG) Vote U387, Office for Research, Innovation, Commercialization and Consultancy Management, (ORICC), Center of Diploma Studies (CeDS) UTHM, Zi Yu Recycle Resources Industrial Sdn. Bhd., laboratory staff of Fakulti Awam dan Alam Sekitar (FKAAS) and Fakulti Mekanikal and Pembuatan (FKMP).

\section{References}

1. S. Sengupta Basu, G. Chakraborty, R.C.J. Thampi, Indian J. Fibre Text. 39,14 (2014)

2. M. Ali, Second International Conference on Sustainable Construction Materials and Technologies, 3, 3, 1441 (2010)

3. H.P.S. Abdul Khalil, M. Siti Alwani, K. Mohd Omar, BioResources 1, 2, 220 (2006)

4. I.Z. Bujang, M.K. Awang, A.E. Ismail, Regional Conference on Engineering Mathematics, Mechanics, Manufacturing \& Architecture (EM*ARC) (2007)

5. Wikipedia. Polyethylene terephthalate (2017)

6. Disposable Products Manufacturing Handbook, (NIIR Project Consultancy Services, Delhi, 2014)

7. L.N. Ji, Appl. Mech. Mater. 312, 406 (2013)

8. F. Shady, R.K. Konda, B. Arijit, Abraham, Nature 180, 4577, 141 (1957)

9. U.K. Thiele, Polyester Bottle Resins, Production, Processing, Properties and Recycling, (Heidelberg, Germany, 2007) 